\title{
The Value of Communities of Practice as a Learning Process to Increase Resilience in Healthcare Teams
}

Janet Delgado

University Institute of Women's Studies, University of La Laguna, University Hospital of the Canary Islands, Neonatal and Intensive Care Unit, La Laguna, Spain

Serena Siow

Department of Family Medicine, Cumming School of Medicine, University of Calgary

Janet M. de Groot

Department of Psychiatry, Oncology and Community Health Sciences, Cumming School of Medicine; University of Calgary

\section{Abstract}

This paper addresses the role that communities of practice (CoP) can have within the healthcare environment when facing uncertainty and highly emotionally impactful situations, such as the current COVID-19 pandemic. The starting point is the recognition that CoPs can contribute to build resilience among their members, and particularly moral resilience. Among others, this is due to the fact that they share a reflective space from which shared knowledge is generated, which can be a source of strength and trust within the healthcare team. Specifically, in extreme situations, the CoPs can contribute to coping with moral distress, which will be crucially important not only to facing crisis situations, but to prevent the long-term adverse consequences of working in conditions of great uncertainty. The purpose of this paper is to analyze how CoP can support healthcare professionals when building moral resilience. To support that goal, we will first define CoP and describe the main characteristics of communities of practice in healthcare. Subsequently, we will clarify the concept of moral resilience, and establish the relationship between CoP and moral resilience in light of the current COVID19 pandemic. Finally, we analyze different group experiences that we can consider as CoP which emerged in the midst of the COVID-19 pandemic to navigate moral problems that arose.

Keywords: communities of practice, vulnerability, moral distress, COVID-19, moral resilience 


\section{Introduction}

Vulnerability is a fundamental aspect in health care (Gjengedal et al. 2013; Delgado 2017). The recognition of our corporeality, dependence and fragility is everywhere in hospitals and health institutions. In this context, healthcare professionals do suffer or witness suffering on a regular basis: they confront death and fragility in a more noticeable way than in daily life (Delgado et al. 2020). To be witness to all of these circumstances in patients' lives has an impact on healthcare professionals' own lives, and it constitutes a form of vulnerability. Healthcare professionals may themselves be prone to more-than-ordinary vulnerability, since they are routinely exposed to stressors that are not ordinarily encountered by most people in their everyday life (Carel 2009). Since these situations cut deeply into the most existential aspects of human life, and place the professionals in a unique position of vulnerability, clinicians suffer when interacting with human health and illness (Ulrich and Grady 2018). In this regard, vulnerability is experienced by professionals because of their profession, as part of their work. Not recognizing this vulnerability may come at a cost not only for healthcare staff, but also for patients and their families. That is, clinician burnout and fatigue are separately associated with major medical errors and perceived medical errors (Tawfik et al, 2018; Welp 2014)

In a public health emergency, such as the COVID-19 pandemic, healthcare professionals are even more prone to moral suffering (Rushton 2018), which include vulnerability experiences and moral distress. Moral suffering is the anguish that occurs when healthcare professionals have to deal with adversities that challenge their own integrity (Rushton 2018). Facing dramatic situations, frontline workers who are directly involved in the diagnosis, treatment and care of patients with COVID19 are at risk of developing mental health problems (Lai et al. 2020) and moral distress (Cacchione 2020). There are at least three ethical issues that are likely to affect healthcare professionals globally: a) their own safety, and the safety of patients, colleagues and families; b) the allocation of limited resources; and c) the changing nature of relationships with patients and their families (Morley et al. 2020). Due to that, there is a necessity for healthcare institutions and professionals to seek sources of support during this pandemic. However, what kind of support can healthcare professionals find, to face these ethical problems? Moral resilience may be an outcome of addressing moral suffering. We understand moral resilience as the ability to effectively navigate crisis situations in response to the moral complexity, confusion, anguish or setbacks of practice (Baratz 2015; Rushton 2016). The question is how in a public health emergency such as the pandemic COVID-19 moral resilience can be fostered in health professionals who face these challenges?

A Community of Practice ( $\mathrm{CoP}$ ) is a group of people interested in the same problem, technique or question that interests them, and who interact regularly to learn together and from each other (Casado and Uria 2019). In the healthcare settings, a $\mathrm{CoP}$ constitutes an intentional space to promote the exchange of experiences arising 
in clinical practice (Delgado et al. 2020). Because of that, our hypothesis is that CoP can be of great value in addressing the moral suffering inherent to the healthcare practice, which is manifested as vulnerability, moral distress, and sometimes burnout. As spaces of openness to share different ethical experiences arising from the practice, especially in unknown and highly emotionally impactful situations, CoPs offer an opportunity to learn together in order to increase resilience collectively.

Our goal is to explore the role that communities of practice (CoP) can have within the healthcare environment when facing unknown and highly emotionally impactful situations, such as the current COVID-19 pandemic. To this end, we first explain what is a CoP, and more particularly a healthcare CoP. Then, we address some modes in which CoPs can promote moral resilience in healthcare professionals to cope with moral distress. We then proceed to analyze these particular problems of moral distress and moral resilience in the context of the current pandemic COVID-19, which show us that moral distress is an issue that must be prevented always, but more intensively in situations which involve a huge emotional impact in healthcare professionals. Finally, we analyze different group experiences that we can consider as CoP which have emerged in the midst of the COVID-19 pandemic to navigate moral problems that arose.

\section{Understanding the key elements of a community of practice}

The notion of CoP was originally introduced to literature by Lave and Wenger in 1991. In this early work, CoP were understood as a type of informal organization oriented to learning with focus on the practical aspects. Since then, the term has been extensively used in education and business sectors, and also in the healthcare field. Lave and Wenger (1991) initially focused on how novices participate in practice, beginning at the periphery of professions, using culturally and historically rich examples. In this context, the situated learning emphasizes the social interactions that support learning within a community of those who practice similar professions or in similar fields (Delgado et al. 2020). Nowadays, CoP can facilitate the ongoing learning process for all professionals, and not only novices.

Following the early work of Wegner et al. (2002), CoP share a basic structure combining three main elements: a domain of knowledge; a community of people who are concerned or interested in the domain; and a set of shared practices that they develop to be effective within the domain. By interacting, the members of CoP obtain several benefits: they share information; help each other to solve problems; share situations, aspirations and needs; explore new ideas; create tools and documents; accumulate knowledge and associate informally. All of this reflects the value that the $\mathrm{CoP}$ create for individual members, as well as for the system or organization, the process of learning together. Consequently, the value of CoP is based on (Wegner et al. 2002):

Connect different or isolated professional experts, 
Diagnose and address recurrent problems whose root causes barriers between teams, Analyze why work units with similar tasks offer different results and work to achieve the highest possible quality and efficiency standard,

Relate and coordinate unrelated activities within the same domain of knowledge.

A CoP has been defined as a group of people who share a practice, care about the same topics, share tacit knowledge and meet regularly to guide each other through their understanding of mutually recognized real-life problems (Pyrko et al. 2017). Pyrko et al. (2017) point out that both the intention to foster trust and the mutual engagement of all members are essential features of a CoP. They proposed developing CoP by "thinking together", in order to advance the understanding of the nature of CoPs and their fundamental learning processes. Some reasons for that are:

Thinking together entails a trans-personal process. Through this process, the members of the CoP thoroughly learn together and from each other in practice, and in this way they become more skillful professionals.

This idea of thinking together additionally emphasizes the possibility of developing learning partnerships and a sense of community through mutual identification. This way of learning is not only related to technical, practical or theoretical knowledge, but also to the understanding of relevance relationships and communities to any particular field of practice.

More particularly focusing on the healthcare field, usually, healthcare CoPs arise to share clinical information about relevant problems in daily work (de Carvalho-Filho et al. 2019), and sometimes it is an urgent clinical problem that initiates the CoP. In these cases, usually a particular patient's case is at the core of the CoP (Young et al. 2018). Accordingly, CoPs constitute an intentional and determined space which allows the exchange of experiences that arise in clinical practice (Delgado et al. 2020). We propose that these experiences could also be a space to exchange thoughts and feelings about the ethical dimension of healthcare, present in all clinical practice, but has not yet been considered in the literature about healthcare CoP. We envision that through "thinking together" about ethical dilemmas in daily work, healthcare professionals will learn together through a process that may foster resilience.

In the next section, we will address why it is so important to deepen understanding the particular circumstances why healthcare professionals face moral suffering (Rushton 2018), and consequently, can experience moral distress.

\section{A silent reality: healthcare professionals' vulnerability, moral distress and burnout}

Healthcare professionals' vulnerability arises from their everyday practice, from the fact that they confront suffering, pain and death day by day. In addition, professionals bring their own vulnerabilities to their encounters with patients. Carel $(2009,218)$ argues that there is "a vulnerability that arises out of the experience of others' 
vulnerability, and this type of vulnerability may require more recognition by the profession. Working as a nurse brings with it an almost daily reminder of the fallibility of human flesh and spirit and the fragility of human life and goods. This, in turn, is a lesson in vulnerability". This learning cannot be explicitly addressed in training, supervision or practice. On the other hand, Carel also maintains that the lesson of vulnerability is not a pessimistic one: vulnerability also suggests a relationship of openness to the world. In order to flourish we must let ourselves be vulnerable: this vulnerability is also the gate to creativity and flourishing (Carel 2009). According to vulnerability theory ${ }^{1}$, vulnerability is not simply a negative condition, but it must be accepted and not ignored (Fineman 2013; 2014) . Indeed, recognizing the positive aspects of vulnerability can improve the experiences of people in terms of isolation and exclusion, because vulnerability is also generative. "Importantly, our vulnerability presents opportunities for innovation and growth, creativity and fulfilment" (Fineman 2012, 96). Some of these positive aspects of vulnerability can improve the relationships in the field of healthcare. To recognize it, we have to consider that there is a shared vulnerability between patients and professionals. Nevertheless, as Barnard maintains, "the ability to translate shared vulnerability into therapeutic relationships requires continuing self-awareness and self-care" (Barnard 2016, 297). Some difficulties seem to appear regarding how to allow healthcare professionals in practice to talk and express their own and shared vulnerability.

Nissim et al. (2019) have developed a qualitative study to evaluate a group intervention based on mindfulness, called Compassion, Presence and Resilience Training (CPR-T), for interprofessional oncology teams. Shared vulnerability emerged in that study as a challenge identified by the participants. The authors recognized three key elements to analyze this experience of vulnerability: a) an organizational culture that does not allow the professionals to show their feelings in adversity, b) vulnerability management in sessions and c) the paradoxical benefits of sharing vulnerability within the team. Regarding the first aspect, the participants worried about being open and showing vulnerability in the group, since they considered that this could diminish their ability to function effectively within the healthcare team when they return to work. Usually in the healthcare environment, any expression of emotionality is traditionally seen as a weakness, although that reality is changing. The participants pointed out that vulnerability is something tacit, which they do not share with patients or colleagues, much less with superiors, since it is seen as a negative feature. Furthermore, people with leadership roles were uncomfortable opening up in front of direct reports and vice versa. Regarding vulnerability management in the sessions, participants described a gradual change through which they could express their vulnerability as the CPR-T was developed.

\footnotetext{
1 The Vulnerability and the Human Condition (VHC) Initiative at Emory University has been developed over the last decade under the leadership of Woodruff Professor of Law Martha Albertson Fineman. See https://web.gs.emory.edu/vulnerability/index.html (Last visited July 8, 2020). In addition, for a broad understanding about vulnerability theory and bioethics, see Delgado 2017.
} 
Although the participants were concerned about the possible consequences of demonstrating vulnerability in front of their team members, they noted that the sessions facilitated mutual trust, empathy and understanding, so that even communication with their colleagues had improved their work (beyond the study group). Finally, regarding the paradoxical benefits of sharing vulnerability within the team, participants commented that CPR-T helped them to recognize the commonalities that they share with their team members, which made them feel more connected to their colleagues and develop a non-critical attitude towards them. All this helped them to build cohesion as well as improve communication between different professions. The participants expressed their surprise upon learning that "they are also vulnerable" (Nissim et al. 2019, 9) and how this awareness helped normalize their own sense of vulnerability and initiate mutual dialogue and learning. Although participants expressed concern about showing vulnerability to their supervisors, participants in managerial positions noted that they became more understanding and responsive to the needs of others.

In addition to the vulnerability experienced by healthcare professionals because of their professional role, moral distress is another source of moral suffering. Moral distress occurs "when a health professional, as a moral agent, cannot or does not act in accordance with his moral judgments (or what he believes to be correct in a particular situation) due to institutional restrictions or internal "(Ulrich and Grady $2018, \mathrm{p} 1)$. In other words, moral distress occurs when health professionals recognize ethical conflicts and their responsibility to respond to them, but cannot make their moral choices. Moral distress can arise when the professionals cannot perform their work in accordance with their moral values. In many cases, the reasons may be directly related to the institution.

We have many examples about health care professional vulnerability, moral distress, and burnout experienced in the workplace, unfortunately, increasing during last years (Dyrbye et al. 2017; Davidson et al. 2018; Squiers et al. 2017). In this regard, there are institutional factors that generate impotence, burnout or moral distress: lack of personnel, lack of administrative support, imbalance in power, inadequate organization of work, lack of communication, work overload, etc. (Moreno 2016). These system problems can lead to feelings of impotence, fear or frustration in the individual healthcare professional. In addition, the perception of an unsafe environment for patients, and the fact that professionals cannot challenge these conditions can exacerbate moral distress (Berlinger 2016). Some of the institutional factors that can trigger moral distress are lack of staff and resources, lack of administrative support, imbalance in power, some styles of leadership, poor organization of work, poor relations between members of the interdisciplinary group, lack of communication, work overload and the precariousness of personnel, among others. In addition, there are also some institutional policies or legislation that can generate moral stress (Moreno 2016). 
Moral distress can be a contributor to burnout (Fumis et al. 2017) as well as unrecognized vulnerability. Burnout is a psychological syndrome that arises in response to chronic stressors at work, a condition in which professionals lose concern and emotional feelings for the people they work with. As a consequence, they come to treat patients as dehumanized persons (Maslach et al. 2001). Burnout is a threedimensional syndrome: (1) emotional exhaustion, (2) cynicism and depersonalization and (3) lack of accomplishment and inefficacy (Maslach et al. 2001, 2016; Fumis et al. 2017). Most burnout research has focused on its profound prevalence rather than seeking to identify the origin of the burnout epidemic, and these efforts are usually focused on increasing resilience and wellness among participants rather than combating problematic changes in how medicine is practiced by physicians nowadays (Squiers et al. 2017).

However, there is an increasing recognition that healthcare organizations need to face burnout and foster well-being, as well as help clinicians to provide the best care to patients, through collective action and targeted investment. In the United States, healthcare organizations are implementing committees and supporting groups in an attempt to reduce burnout among their clinicians, nurses and physicians. The National Academy of Medicine (NAM), has a strong commitment on addressing these problems, and they have designed the vast initiative "Action Collaborative on Clinician Well-Being and Resilience", which is one of the most important initiatives developed in this area. As part of this project, the NAM is promoting a network of organizations of the Action Collaborative on Clinician Well-Being and Resilience ${ }^{1}$. Another initiative to address burnout has been the Institute for Healthcare Improvement Framework for Improving Joy at Work (Perlo et al, 2017).

\section{The COVID-19 pandemic complexity as a moral suffering trigger for healthcare providers}

In exceptional situations of great physical and emotional burden, such the pandemic COVID-19, ethical questions involving huge emotional suffering increases exponentially. No other previous situation has explicitly exposed the vulnerability of healthcare professionals worldwide to the public. With the current public health crisis, several factors that increase stress, fear and moral distress in health professionals, increasing the mental load of health workers, has been added to their more than ordinarily vulnerable everyday practice. During the peak period of the pandemic, the increasing number of cases, overwhelming workload, lack of personal protective equipment (PPE), media coverage, lack of specific medications, and feelings of being inadequately supported has been identified as factors associated with experiences of psychological burden among healthcare workers exposed to COVID- 19 (Lai et al. 2020).

\footnotetext{
1 The information about the Action Collaborative on Clinician Well-Being and Resilience, developed by the NAM, in available in: https://nam.edu/initiatives/clinician-resilience-and-well-being/
} 
These are some aspects that have been identified as triggering moral distress during the current pandemic:

a) The need to prioritize scarce resources such as ventilators, intensive care beds, blood, etc., generates moral distress (Berlinger et al. 2020; DePierro et al. 2020). In addition, the decision making process about the withdrawal of life support treatments, in this case, would occur despite the fact that the treatments are not objectively futile and that the patients do not reject these interventions, but mainly due to the lack of availability of resources. In Intensive Care Units, during the COVID19 pandemic, professionals have experienced feelings of disorientation, worry, loss of control, and helplessness (Kok et al. 2020).

b) Primary Care professionals have been overwhelmed, having to face complex decision-making that generates great moral distress, since it is a new disease with great uncertainty regarding treatment, which entails establishing a relationship with patients different from usual practice (having to do triage, telematic consultations, distance or using PPE), and in a context of scarce resources for both care and protection of professionals (Melguizo et al. 2020).

c) Health professionals cannot refuse to care for patients. However, if there is a lack of personal protective equipment PPE and they are at risk of contracting the disease, should they refuse to treat their patients? When does work-based risk become unacceptable? Is there a time when health professionals have the right not to treat seriously ill patients if their PPE is inadequate or if they do not have it? It is essential to treat patients regardless of their disease. But are there limits to this duty? How much risk is too much risk? (Kok et al. 2020; Sheather and Chisholm 2020). The lack of PPE highlights the obligations of healthcare professionals to take care of themselves (Declaration of the World Medical Association in Geneva 2017; ParsaParsi 2017) not only because it is necessary to improve the work life of healthcare providers as part of the quadruple aim (Bodenheimer and Sinsky 2014), but also because they are extremely valuable assets for treating patients in the context of a pandemic. The Canadian Medical Association conducted a poll of Canadian physicians showing $74 \%$ were somewhat anxious or very anxious about PPE supply (CMA April 2020), and that three quarters of physicians working hospitals were uncertain of their PPE stock or supply (CMA April 2020). In any case, this kind of uncertainty about PPE availability and difficult decision-making generates moral distress, as healthcare professionals feel obligated to continue to provide care.

Moral distress has been identified as a predictor of burnout (Rushton et al. 2015; Fumis et al. 2017) and research has explored the prevalence of burnout in healthcare professionals during the COVID-19 pandemic. In a public health crisis as the current pandemic, healthcare professionals have to contribute increased efforts into their activities for extended working hours. In addition, the constant use of PPE, and the physical fatigue and mental pressures on the unknown disease make the working hours tremendously exhausting (Talee et al. 2020). Other studies have noted the 
psychological impact of COVID-19 to healthcare workers. A study in Italy where $49 \%$ showed post traumatic stress, $25 \%$ depression, $20 \%$ anxiety, and $22 \%$ high perceived stress (Rossi et al. 2020). A study in China showed that of healthcare workers treating patients with COVID-19, 50\% reported symptoms of depression, 34\% reported insomnia, $45 \%$ reported symptoms of anxiety, and $72 \%$ reported distress (Lai et al. 2020). Another study of frontline nurses in Wuhan China reported that nurses experience moderate burnout and a high level of fear, with half of nurses reporting moderate or high burnout in all burnout dimensions (Hu et al. 2020). According to the results of a study in Ecuador during the COVID-19 pandemic (Vinueza et al. 2020), more than $90 \%$ of medical and nursing professionals had moderate-severe burnout syndrome. These results were associated with profession (physicians experienced higher burnout than nurses), age (the youngest were the most affected) and gender (women were more affected than men). In a systematic review addressing the prevalence of depression, anxiety, and insomnia among healthcare professionals during the COVID-19 pandemic, the evidence suggests that a significant proportion of healthcare professionals have experienced mood and sleep disorders, highlighting the need to establish ways to mitigate mental health risks and adjust interventions to cope with it and minimize the risks factors (Pappa et al. 2020). In addition, medical and nursing students have also experienced stress and anxiety during the pandemic (Al-Rabiaah et al. 2020). A study in Iran of hospital workers showed $53 \%$ experienced high levels of burnout during the COVID-19 pandemic (Jalili et al, 2020). These studies are worrisome, as the existing rates of mental health illness and occupational burnout in healthcare prior to the pandemic were significant, with over half of physicians and one third of nurses experiencing burnout in the United States (McHugh et al. 2011, Shanafelt et al. 2012). An editorial in a Canadian newspaper highlights the potential crisis of worsening mental health issues from the pandemic, in physicians already experiencing high mental health and burnout rates (Horton 2020). The parallel pandemics of burnout and post traumatic stress disorder received further attention following the death by suicide of Dr Lorna Breen, the medical director of the emergency department of New York Presbyterian Hospital ${ }^{1}$. Further research is ongoing exploring the psychological impact and effect of burnout from the pandemic. For example, a psychiatrist in Montreal is recruiting healthcare workers for a study on factors associated with burnout (https://burnout.mhicc.org/), while a team in Halifax is conducting research on burnout in healthcare workers. (https://researchns.ca/2020/05/05/preventing-burnout-among-front-line-careworkers-to-fight-covid-19-screen-and-intervene/)

Considering all this complexity, to address the psychological and emotional needs by providing the healthcare professionals and students with adequate support is essential to improve the management of this situation. Some ways that have been proposed to support them are: a) considering their conditions, b) presenting

1 The New York Times published the report about this case on April 27, 2020. Available in: https://www.nytimes.com/2020/04/27/nyregion/new-york-city-doctor-suicide-coronavirus.html 
solutions, c) increasing their awareness, d) encouraging them, and e) acknowledging their importance (Talee et al. 2020). In addition, to increase the resilience of healthcare professionals seems to be a necessary goal to cope with the specific difficulties triggered by public health emergencies. To foster healthcare professionals' resilience, we show how CoP can provide the adequate space for building the healthcare professionals resilience.

\section{How to foster moral resilience through a CoP in the context of the COVID-19 pandemic}

The most common approach when talking about ethics in organizations is the use of an individualistic vision in which each person is morally responsible for their behavior; consequently, the interventions focus on the health care of the professional. However, another way to approach ethics in health organizations is to see each person as a member of a community or team, where the understanding of individual ethical behaviors must be complemented by knowledge and exploration of the organization's moral and social structure (Moreno 2016). Despite being a source of suffering for healthcare professionals, vulnerability and moral distress can also act as a spring to open the field of reflection and dialogue from which to generate change at the collective or institutional level (Carel 2009, Fineman 2013, 2014, Moreno 2016). In this regard, our thesis is that CoP can be a source of moral resilience for health care professionals to cope with vulnerability, moral distress and other forms of moral suffering.

In the healthcare environment, resilience plays an important role for workers. A way to foster workplace well-being and engagement is training for resilience, developing good mental health and subjective well-being. Resilience training has a number of wider benefits that include enhanced psychosocial functioning and improved performance (Robertson et al. 2005). All professions in healthcare experience similar effects in relation to the stressful conditions of work. This common aspect offers an opportunity to design and implement interprofessional approaches that can enhance the capacity for resilience among teams of coworkers. For this purpose, it is necessary an institutional culture that prioritizes training and cultivating specific skills and attitudes for promoting resilience to all members of the health care team, which also include students (Haramati and Weissinger 2015). Resilience has been studied mainly in regard to stress. But what about ethical conflicts and problems that workers have to deal with?

Initially the term of moral resilience was developed as moral courage. Lachman $(2007,131)$ defines moral courage as the "capacity to overcome fear and stand up for his or her core values; the willingness to speak out and do what is right in the face of forces that would lead a person to act in some other way; it puts principles into action". In her latest work, she also develops the concept of moral resilience, defining it as "the ability to deal with an ethically adverse situation without lasting effects of moral distress and moral residue" (Lachman 2016, 123). She adds that this requires 
morally courageous action, activating needed supports and doing the right thing. In addition, she argues "the virtue of moral courage is necessary to meet the ethical obligations of the profession" (Lachman 2016, 123). Rushton (2016) highlights that moral resilience is a concept under construction, and it is a way to transform the deep despair and impotence associated with morally distressing situations. Moral resilience can be understood as the ability to preserve or restore integrity in response to various types of moral adversity (Rushton 2018).

We acknowledge that healthcare professionals are thought to be highly resilient. A Canadian study of physicians showed that despite over 30\% experiencing high levels of burnout, $60 \%$ of physicians said their overall mental health was flourishing and $82 \%$ reported high levels of resilience (CMA 2018). In the COVID-19 pandemic, Hu et al. (2020) found a moderately negative correlation between frontline nurses' burnout, anxiety, and depression with the self-efficacy and resilience. Thus, as nurses have greater more self-efficacy and resilience, they may experience less mental health problems.

Gujral et al. (2020) have proposed some strategies to increase resilience in healthcare professionals during the COVID-19 pandemic:

a) Find time for self-care: give employees the opportunity to attend the practice of meditation, acupuncture, yoga therapy or massage therapy as well as a weekly mindfulness meditation session guide.

b) Breathing practice: offering 15-minute breathing sessions three times a week by teleconference for anyone working within the healthcare system as a reminder of focus on breathing practice.

c) Gratitude practices: Finding the opportunity for gratitude as a powerful practice to heal, energize, and empower.

Although these interventions are important, all of them are focused on an individual perspective, that is, to promote individual moral resilience. They must be complemented with a collective perspective. In addition, these interventions do not address the systemic factors which are thought to contribute to moral distress and burnout. A collective and systemic perspective is of great importance, given recent research that finds physicians have greater resilience than the general working population (West et al, 2020) and that even highly resilient physicians may experience burnout. Thus, individual resilience alone is not sufficient to prevent burnout or moral distress. Collective perspectives also have the potential to improve systems through advocacy. It is also necessary to consider whether resilience as currently assessed, equates with moral resilience.

In the light of this way of thinking, and according to Delgado et al. (2020), the exchange of experiences that is shared within the CoPs is an essential factor in building and maintaining moral resilience. It allows for a change in relationship from a distressing situation by shifting the mindset that the distressing experience is 
completely negative. From this starting point, strategies to collectively navigate ethically complex situations can be developed. Culture and systems play a crucial role in supporting physicians' moral resilience, in terms of building an environment of ethical practice. In this regard, CoP seems to be one ideal strategy for the flourishing of resilience among the healthcare team. Fostering CoPs as a process that encourages healthcare professionals to address ethical dilemmas together has the potential to build culture and system change, which reciprocally enhances personal resilience.

One concern that can arise regarding the $\mathrm{CoP}$ as a strategy to collectively build resilience is if this process can imply some risks. We believe that CoP can facilitate the increase of resilience among the participants through the relationships, dialogue, trust and continuity (Delgado et al. 2020). However, who should facilitate or moderate these discussions? Since the emotional management of these groups is complex and can be iatrogenic if they are not carried out by people trained, CoP pursuing the goal of increasing moral resilience should be facilitated by experts with experience facilitating groups, addressing emotional needs, understanding ethical complexities and building personal resilience. The question now is who should be these experts? The selection and composition of these experts influence effectiveness of the CoP to achieve its goal of moral resilience.

\section{Practical approach: analyzing examples in the context of the COVID-19 pandemic}

During the COVID-19 pandemic, the healthcare providers have shown great strength and resilience. Liu et al. (2020) found that healthcare nurses and doctors working in Hubei, China, used multiple support systems and self-management skills to relieve stress. However, the sense of helplessness over the suffering of the patients and the sudden loss of life were identified as painful. Some professionals believed that they could cope with their emotional stress without professional support. However, professional psychological counseling and support systems and crisis interventions should be made available to those seeking formal assistance. "With logistical support from their hospital and peer support and encouragement among colleagues, they had a sense of safety and felt they were not alone" (Liu et al. 2020, e795).

Across the world, healthcare providers were called to step up to the surge of patients requiring hospitalization. Many were redeployed from community settings, often without direct experience caring for patients with infectious or respiratory disease. The sense of responsibility to provide care in a competent manner led to the provision of multiple educational resources. Many medical organizations, educational institutions, and healthcare organizations provided educational webinars to learn more about COVID-19 with a focus on clinical aspects of managing patients with COVID-19. These webinars provided an opportunity for healthcare professionals to share experiences within their respective clinical settings. Many international physicians provided opportunities to share their experiences with others around the 
world via teleconference to support others' efforts to contain the pandemic ${ }^{1}$. The emergence of online forums to share experiences related to COVID-19 was observed, as the Doctors of British Columbia initiative (https://www.doctorsofbc.ca/news/new-online-forum-physicians-collaboratecovid-19). An international online forum for critical care physicians provided an opportunity to share experiences surrounding healthcare personnel management, isolation and quarantine procedures, respiratory therapy, antivirals, and indications for Intensive Care Unit admission and discharge (Bo et al. 2020). A report of G-MED's Global Physician Online Community showed physicians from over twenty countries contributing information about four themes: epidemiology, guidelines, preparedness, and treatment approaches (IpsosMORI 2020). The use of social media, including Facebook and Twitter to gain information from other healthcare professionals has been noted in a New York Times article ${ }^{2}$. Although not formally called CoPs, we witnessed healthcare professionals engage with colleagues around the world to share information and learnings together with the common goal of curbing the pandemic. In this regard, Tan and Roach, who met via Twitter, co-wrote a piece on Allyship (Tan \& Roach 2020) as global anti-racism protests enhanced awareness of the greater likelihood of Black Americans, indigenous people and people of color, experiencing not only discrimination and police brutality, but also developing COVID-19 itself and its adverse outcomes, including death (Thakur et al, 2020; Elbaum 2020).

More specifically, CoPs that address healthcare professionals' well-being, with the intention to prevent burnout and increase ability to cope with moral distress have been developed in response to the COVID-19 pandemic. Experts or groups of experts as in the examples below, of the Virtual Moral Resilience Rounds and the COVID Ethics series are helpful to providing examples of learning from experience and conveying diverse ways of thinking about moral challenges. In groups, expert facilitators may support validation of and exploration of challenges or encourage others to provide perspectives. These examples of CoPs addressing moral distress and building resilience are described here:

Virtual Moral Resilience Rounds have emerged at Johns Hopkins Hospital (US) to proactively have discussions about the COVID-19 pandemic ${ }^{3}$. These weekly one-hour sessions invite multidisciplinary clinicians to attend to discuss ethical challenges, with the goal of acknowledging distress and finding solutions. These sessions are held on Zoom and facilitated by C. H. Rushton, a physician, and a philosopher, with broad expertise on moral distress and moral resilience.

\footnotetext{
${ }^{1}$ More information is available in these websites: a)https://news.cgtn.com/news/2020-03-07/ChinaItaly-doctors-share-experiences-of-COVID-19-control-online-OFi0gryDVS/index.html; b) http://en.people.cn/n3/2020/0324/c90000-9671699.html 2Information available in: https://www.nytimes.com/2020/03/18/well/live/coronavirus-doctorsfacebook-twitter-social-media-covid.html 3Information available in: https://www.advisory.com/research/physician-executivecouncil/prescription-for-change/2020/05/moral-resilience-rounds.
} 
In Calgary, Canada, a team of psychiatrists, mental health clinicians, and family physicians established a partnership to provide an opportunity for connection and support amongst healthcare professionals during the COVID-19 pandemic. Online spaces offer physicians, and separately, continuing care facility staff, the chance to meet and share experiences with peers. The online space for physicians is called "Virtual Doctors' Lounge" and acknowledges the challenges of providing care during the pandemic including ethically complex situations. It has been piloted to a group of family physicians providing care in hospital settings. As continuing care staff have been greatly affected in Canada with high numbers of COVID-19 cases and deaths, an online group provides the opportunity for staff to receive support. These online group sessions promote sharing of experiences, acknowledging emotional distress, normalizing experiences, and providing support to others. They are facilitated by psychiatrists and mental health clinicians with expertise in group therapy.

In Alberta, Canada, different experiences can be identified as emerging or strengthening frequency of CoP meetings in the midst of the Covid-19 pandemic to navigate healthcare professionals problems that arose.

1) Alberta Health Services (AHS) Zoom Room: This biweekly one hour session addressed numerous topics relevant to the pandemic and physicians, including but not limited to PPE availability, domestic violence during the pandemic, Zoom use. The series began with an expert-led presentation on one of the topics followed by participants' sharing of their own experiences and perspectives. Outcomes of the sessions were shared with AHS leaders and often led to Tip sheets that others could access.

2) Psychosocial oncology spontaneously developed a clinical discussion group addressed all matters related to clinical practice including technology.

3) Psychodynamic psychotherapy clinicians who previously met bi-monthly, met weekly to share wisdom regarding practical and clinical implications of COVID-19 in psychotherapy practices. This included change to virtual practice, clinical presentations and therapist challenges related to COVID-19 including Zoom fatigue and methods to manage it. Texts, email information and papers are shared between meetings.

Dr. Mamta Gautum, a Canadian psychiatrist with expertise in physician health held daily online support groups for physicians across Canada during the pandemic. Many physicians entered the pandemic burnt out, and thus were at risk of medical errors. Four distinct stages were evident through the course of the first surge of the pandemic: readiness, response, reassurance and recovery. Challenges discussed varied from frontline issues including PPE limitations and, $\mathrm{d}$ for those not at the frontline, there was adjustment to clinical practice and delivering virtual care while working from home, balancing childcare or resilience, partner job loss. These sessions provided a space for physicians to share their experiences and receive expert advice on strategies to address personal challenges and build resilience. 
A COVID Ethics Series at Seton Hall University and Hackensack Meridian Medical School arose in recognition of the value of many and diverse people discussing challenging ethical issues. The series was organized by Dr. Pilkington and includes a panel of experts from medicine, nursing and health sciences, as well as philosophers, ethicists, economists and lawyers. Topics included but were not limited to: Intention and Limitations of Aid, Vulnerability and Dependence during the time of COVID-19 and Discrimination intensified during Covid-19. The series aimed to enhance the capacity of students and healthcare practitioners to practically reason about morally challenging topics (Pilkington, 2020).

\section{Conclusion}

Healthcare professionals are exposed to complex challenges in daily work that increase vulnerability and moral distress, which are heightened in the situations of extreme stress, such as the current COVID-19 pandemic. We examined CoP as a process to build resilience, and provided examples of healthcare providers coming together to share information, experiences, wisdom and perspectives with a common goal. This process of sharing common experiences in a group setting can also be valuable to build resilience, not only for the individual professional, but also towards a culture of ethical practice. Using CoP, our intention is to recognize both the individual and the system's responsibility towards shaping the working environment in a way that promotes safe and effective care. CoP have demonstrated value during the pandemic and we theorize that CoP may be an effective strategy to increase moral resilience of healthcare professionals collectively, and exist beyond the duration of the pandemic. Finally, we emphasize the importance of promoting ethical reflection grounded on practice in order to respond to the everyday ethical challenges of healthcare professionals. "There are limits to thinking of professional ethics in terms of virtues- being caring, being compassionate, being respectful- if healthcare professionals see few ways to put these virtues into practice(...) Thinking about the complex systems as a "moral space" that must always be open to the discussion of questions of right and wrong action, of justice and injustice, may help us grapple with the continuing challenge of creating and sustaining health care systems that are safe, effective, compassionate and just" (Berlinger, 2016, p. 176).

\section{References}

[1] Al-Rabiaah A, Temsah MH, Al-Eyadhy AA, et al. Middle East Respiratory Syndrome-Coronavirus (MERS-CoV) associated stress among medical students at a university teaching hospital in Saudi Arabia. J Infect Public Health. 2020;13(5):687-691. doi:10.1016/j.jiph.2020.01.005

[2] Baratz, L. (2015). Israeli teacher trainees' perceptions of the term moral resilience, Journal for Multicultural Education, 9 (3), 193 - 206.

[3] Berlinger, N. (2016). Are workaround ethical? Managing Moral Problems in Health Care Systems. New York, Oxford University Press. 
[4] Berlinger, N., Milliken, A., Guidry, L. K. et al. (2020). Ethical Framework for Health Care Institutions Responding to Novel Coronavirus SARS-CoV-2 (COVID-19) Guidelines for Institutional Ethics Services Responding to COVID-19 Managing Uncertainty, Safeguarding Communities, Guiding Practice. The Hastings Center.

[5] Bodenheimer, T. and Sinsky, C. (2014). From Triple to Quadruple Aim: Care of the Patient Requires Care of the Provider. Annals of Family Medicine, 12 (6), 573-576.

[6] Cacchione, P. Z. (2020). Moral Distress in the Midst of the COVID-19 Pandemic. Clinical Nursing Research. https://doi.org/10.1177/1054773820920385.

[7] Canadian Medical Association (CMA). (April 2020). CMA Rapid Poll on the Supply of Personal Protective Equipment and Mental Health Impact of COVID-19. https://www.cma.ca/sites/default/files/pdf/Survey/CMArapid-poll-Executive-summary-2 EN.pdf

[8] Canadian Medical Association (CMA). (April 2020)CMA Rapid Poll on the Supply of Personal Protective Equipment. https://www.cma.ca/sites/default/files/pdf/Survey/CMA-Survey-Supplyof-PPE E.pdf

[9] Canadian Medical Association (CMA). (October 2018). National Physician Health Survey (October 2018). https://www.cma.ca/sites/default/files/2018-11/nph-survey-e.pdf

[10] Carel, H. (2009). A reply to 'Towards an understanding of nursing as a response to human vulnerability' by Derek Sellman: vulnerability and illness. Nursing Philosophy, 10, 214-219.

[11] Casado, A., Uria, E. (2019). Cultivando comunidades de práctica en la extensión universitaria: artes escénicas y performativas en el campus de Gipuzkoa". Periférica Internacional: Revista para el análisis de la cultura y el territorio, 20, 100-107.

[12] Davidson, J., Mendis, J., Stuck, A., DeMichele, G., Zisook, S. (2018). Nurse Suicide: Breaking the Silence. NAM Perspectives, Discussion Paper.

[13] de Carvalho-Filho, M. A., Tio, R. A., Steinert, Y. (2019). Twelve tips for implementing a community of practice for faculty development. Med Teach, 1,1-7.

[14] Delgade J, de Groot J, McCaffrey G, Dimitropoulos, G., Sitter, K.C., Austin, W. (2020) Communities of practice: acknowledging vulnerability to improve resilience in healthcare teams. Journal of Medical Ethics. doi:10.1136/medethics-2019-105865.

[15] Delgado J. (2017). The relevance of the ethics of vulnerability in bioethics. Les ateliers de l'éthique The Ethics Forum, 12 (2-3), 253-79.

[16] DePierro, J., Lowea, S., Katzb, C. (2020) Lessons learned from 9/11: Mental health perspectives on the COVID-19 pandemic. Psychiatry Research, 288, 113024. 
[17] Dyrbye, L., Shanafelt, T., Sinsky, C., Cipriano, P., Bhatt, J., Ommaya, A. et al. (2017). Burnout among health care professionals a call to explore and address this under recognized threat to safe, High- Quality. NAM Perspectives, Discussion Paper.

[18] Elbaum, A. (2020). Black lives in a pandemic: implications of systemic injustice for end of life care. Hastings Center Report, 50(3): 58-60.

[19] Fineman, M. (2012). "Elderly" as vulnerable: Rethinking the nature of individual and societal responsibility. The Elder Law Journal. 20 (1), 71-112.

[20] Fineman, M. A. (2013). Equality, Autonomy and the Vulnerable Subject in Law and Politics, in Fineman, M. A., Gear, A. (eds). Vulnerability. Reflections on a New Ethical Foundation for Law and Politics. New York, Ashgate Publishing.

[21] Fineman, M. A. (2014). Vulnerability, Resilience, and LGBT Youth. Temple Political \& Civil Rights Law Review, Forthcoming; Emory Legal Studies, 14292.

[22] Fumis R.R.L., Junqueira G.A., de Fátima A., Vieira J.M. (2017). Moral distress and its contribution to the development of burnout syndrome among critical care providers. Ann Intensive Care, 7(1), 71. doi:10.1186/s13613017-0293-2.

[23] Gjengedal, E., Ekra E. M., Hol, H., Kjelsvik, M., Lykkeslet, E., Michaelsen, R. et al. (2013). Vulnerability in health care - reflections on encounters in every day practice. Nursing Philosophy, 14, 127-138.

[24] Gujral, H., Rushton, C.H., Rosa, W.E. (2020) Action Steps Toward a Culture of Moral Resilience in the Face of COVID-19. Journal of Psychosocial Nursing. 58 (7), 1-4.

[25] Haramati, A. and Weissinger, P. (2015). Resilience, Empathy, and Wellbeing in the Health Professions: An Educational Imperative. Global Advances in Health Medicine, 4(5), 5-6.

[26] Horton, J. (May 8, 2020). Doctors' disorders: After COVID-19, physicians will have to face a crisis of another sort. Contribution to The Globe and Mail. https://www.theglobeandmail.com/opinion/article-doctors-disordersafter-covid-19-physicians-will-have-to-face-a/.

[27] Hu, D., Kong, Y., Li, W., Han, Q., Zhang, X., Zhu L. X. (2020) Frontline nurses' burnout, anxiety, depression, and fear statuses and their associated factors during the COVID-19 outbreak in Wuhan, China: A large-scale crosssectional study. $E$ Clinical Medicine, https://doi.org/10.1016/j.eclinm.2020.100424.

[28] IpsosMORI (2020) Medical crowdsourcing: What are Physicians communicating during COVID-19? Qualitative analysis of G-MED Global Physician Online Community.

[29] https://www.ipsos.com/sites/default/files/ct/publication/documents/20 20-03/what-are-physicians-communicating-during-covid-19.pdf 
[30] Jalili, M., Niroomand, M., Hadavand, F., Zeinali, K., Fotouhi, A. (2020). Burnout among healthcare professionals during COVID-19 pandemic: a cross-sectional study. medRxiv, doi: https://doi.org/10.1101/2020.06.12.20129650.

[31] Kok, N., Hoedemaekers, A., van der Hoeven, H., Zegers, M., van Gurp, J. (2020). Recognizing and supporting morally injured ICU professionals during the COVID-19 pandemic. Intensive Care Med, https://doi.org/10.1007/s00134-020-06121-3.

[32] Lachman, V. (2007). Moral courage: a virtue in need of development? Medsurg nursing, 16(2), 131-133.

[33] Lachman, V. D. (2016). Moral Resilience: Managing and Preventing Moral Distress and Moral Residue. Medsurg Nursing, 25 (2), 121-124.

[34] Lai J., Ma S., Wang Y., Cai, Z., Hu, J., Wei, N. et al. (2020). Factors associated with mental health outcomes among health care workers exposed to coronavirus disease 2019. JAMA Netw Open, 3: e203976.

[35] Lave J, Wenger E. (1991). Situated learning. Legitimate peripheral participation. Cambridge UK: Cambridge Universities Press.

[36] Liu, Q., Luo, D., Haase, J. E., Guo, Q., Wang, X.Q., Liu, S., Xia, L. et al. (2020) The experiences of health-care providers during the COVID-19 crisis in China: a qualitative study. Lancet Glob Health, doi: 10.1016/S2214-109X(20)302047

[37] Maslach, C., Leiter, M.P. (2016). Understanding the burnout experience: recent research and its implications for psychiatry. World Psychiatry, 15, 103-11. doi: 10.1002/wps.20311

[38] Maslach, C., Schaufeli, W.B., Leiter, M.P. (2001). Job burnout. Annu Rev Psychol, 52, 397-422. doi:10.1146/annurev.psych.52.1.397

[39] McHugh, M.D., Kutney-Lee, A., Cimiotti, J.P., Sloane, D.M., Aiken, L.H. (2011). Nurses' Widespread Job Dissatisfaction, Burnout, And Frustration With Health Benefits Signal Problems For Patient Care. Health Aff (Millwood) Health Aff (Millwood). 2011 Feb; 30(2): 202-210. doi: 10.1377/hlthaff.2010.0100.

[40] Melguizo, M., Hortal, J., Padilla, J. (2020). Medicina basada en las «existencias» o soporte ético para las decisiones difíciles. Actualización en Medicina de Familia, 16 (5).

[41] Moreno, C. (2016). Conflictos éticos y acciones de resistencia: los profesionales de atención primaria de Mallorca frente a los recortes en el sistema público de salud. Doctoral Thesis. Universitat de les Illes Balears, Mallorca.

[42] Morley, G., Grady, C., McCarthy, J., Ulrich, C. M. (2020). Covid-19: Ethical Challenges for Nurses, Hastings Center Report 50, 1-5. doi: 10.1002/hast.1110.

[43] Nissim, R., Malfitano, C., Coleman, M., Rodin, G., Elliott, M. (2019). A Qualitative Study of a Compassion, Presence, and Resilience Training for 
Oncology Interprofessional Teams. J Holist Nurs, 37(1), 30-44. doi:10.1177/0898010118765016.

[44] Pappa, S., Ntell, V., Giannakas,T., Giannakoulis, V. G., Papoutsi, E., Katsaounou, P. (2020). Prevalence of depression, anxiety, and insomnia among healthcare workers during the COVID-19 pandemic: A systematic review and meta-analysis. Brain, Behavior, and Immunity. doi.org/10.1016/j.bbi.2020.05.026.

[45] Parsa-Parsi, R. W. (2017). The Revised Declaration of Geneva. A ModernDay Physician's Pledge. JAMA, 318(20):1971-1972. doi:10.1001/jama.2017.16230.

[46] Perlo J, Balik B, Swensen S, Kabcenell A, Landsman J, Feeley D. (2017). IHI Framework for Improving Joy in Work. IHI White Paper. Cambridge, Massachusetts: Institute for Healthcare Improvement. (Available at ihi.org)

[47] Pilkington B. (2020). Lessons from COVID-19: From moral distress to an interprofessional ethics community. APHC-PFO newsletter. July 2020. in press

[48] Pyrko I, Dörfler V, Eden C. (2017). Thinking together: what makes communities of practice work? Human Relations, 70(4), 389-409.

[49] Robertson, H., Elliott, A., Burton, C. Iversen, L., Murchie, P., Porteous, T. et al. (2016). Resilience of primary healthcare professionals: a systematic review. British Journal of General Practice, 66(647):e423-33.

[50] Rossi R, Socci V, Pacitti F, Di Lorenzo G., Di Marco A. et al. Mental Health Outcomes Among Frontline and Second-Line Health Care Workers During the Coronavirus Disease 2019 (COVID-19) Pandemic in Italy. JAMA Netw Open. 2020;3(5):e2010185. doi:10.1001/jamanetworkopen.2020.10185.

[51] Rushton, C.H. (2016). Moral resilience: A capacity for navigating moral distress in critical care. AACN Advanced Critical Care, 27 (1), 111-119.

[52] Rushton, C.H., Batcheller, J., Schroeder, K., Donohue, P.(2015). Burnout and Resilience Among Nurses Practicing in High-Intensity Settings. Am J Crit Care, 24 (5), 412-420.

[53] Rushton, C.H.(ed.) (2018) Moral Resilience: Transforming Moral Suffering in Healthcare. New York, Oxford University Press.

[54] Shanafelt, T.D., Boone, S., Tan, L., Dyrbye, L.N., Sotile, W., Satele, D., et al. Burnout and satisfaction with work-life balance among US physicians relative to the general US population. Arch Intern Med. 2012;172(18), 13771385. doi:10.1001/archinternmed.2012.3199.

[55] Sheather, J., Chisholm, J. (2020). The duty to treat: where do the limits lie? BMJ blog https://blogs.bmj.com/bmj/2020/05/12/the-duty-to-treatwhere-do-the-limits-lie/

[56] Squiers, J., Lobdell, K., Fann, J., and DiMaio, J. M. (2017). Physician Burnout: Are We Treating the Symptoms Instead of the Disease? Annals of Thoracic Surgery; 104, 1117-1122. 
[57] Talaee, N., Varahram, M., Jamaati, H., Salimi, A., Attarchi, M., Kazempour dizaji, M. et al. (2020) Stress and burnout in health care workers during COVID-19 pandemic: validation of a questionnaire. Journal of Public Health: From Theory to Practice. https://doi.org/10.1007/s10389-020-01313-z.

[58] Thakur, N., Lovinsky-Desir, S., Bime, C., Wisnivesky, J.P.,, Celedon, J.C., on behalf of The Health Equity and Diversity Committee of the American Thoracic Society. (2020). The structural and social determinants of the racial/ethnic disparities in the U.S. Covid 19 pandemic: what's our role? Am J Respir Crit Care Med. https://doi.org/10.1164/rccm.202005-1523PP

[59] Tawfik, D.S., Profit, J., Morgenthaler, T.I., Satele, D.V., Sinsky, C.A., Dyrbye, L.N., et al. (2018). Physician Burnout, Well-being, and Work Unit Safety Grades in Relationship to Reported Medical Errors. Mayo Clin Proc;93(11):1571-1580. doi:10.1016/j.mayocp.2018.05.014

[60] Ulrich, C. M., Grady, C. (eds.) (2018). Moral Distress in the Health Professions. Cham, Springer International Publishing.

[61] Vinueza, A. F., Aldaz, N. R., Mera, C. M., Pino, D. P., Tapia E. C., Vinueza, M. F. (2020). Síndrome de Burnout en médicos/as y enfermeros/as ecuatorianos durante la pandemia de COVID-19. SciELO Preprints. https://doi.org/10.1590/scielopreprints.708

[62] Welp AA, Meier L, Manser T. (2014). Emotional exhaustion and work-load predict clinician-rated and objective patient safety. Front Psychol; 5: 1573.

[63] Wenger, E., McDermott, R., Snyder, W.M. (2002). Cultivating Communities of Practice. Boston, Harvard Business School Press.

[64] West, C.P., Dyrbye, L.N., Sinsky, C., Trockel, M.,Tutty, M., Nedelec, L., et al. (2020). Resilience and burnout among physicians and the general US working population. JAMA Network Open; 3(7): e209385.

[65] World Medical Association Declaration of Geneva. The Physician's Pledge Adopted by the 2nd General Assembly of the World Medical Association, Geneva, Switzerland, September 1948 and amended by the 22nd World Medical Assembly, Sydney, Australia, August 1968 and the 35th World Medical Assembly, Venice, Italy, October 1983 and the 46th WMA General Assembly, Stockholm, Sweden, September 1994 and editorially revised by the 170th WMA Council Session, Divonne-les- Bains, France, May 2005 and the 173rd WMA Council Session, Divonne-les-Bains, France, May 2006 and the WMA General Assembly, Chicago, United States, October 2017.

[66] Xiao-Bo H, Poonyathawon S, Semedi BP, Xiao-Yi Z, Wei F, Da-Wei W, et al. International-focused Online Forum: A Good Way to Jointly Manage the COVID-19 Pandemic for Global Critical Care Community. Indian J Crit Care Med 2020;24(4):283-284.

[67] Young, P. D., Rushton C. H. (2017). A concept analysis of moral resilience. Nursing Outlook, 65 (5), 579-587. 